\title{
Jumlah Pemenuhan dan Pola Penggunaan Obat Program Rujuk Balik di Apotek Wilayah Gedebage Kota Bandung
}

\author{
Surya Dwi Sembada ${ }^{1}$, Kuswinarti², Nita Arisanti ${ }^{3}$ \\ ${ }^{1}$ Fakultas Kedokteran Universitas Padjadjaran \\ ${ }^{2}$ Departemen Farmakologi dan Terapi, Fakultas Kedokteran Universitas Padjadjaran \\ ${ }^{3}$ Departemen Ilmu Kesehatan Masyarakat, Fakultas Kedokteran Universitas Padjadajaran
}

\begin{abstract}
Abstrak
Indonesia memberlakukan Jaminan Kesehatan Nasional (JKN) awal tahun 2014 yang dikelola oleh Badan Penyelenggara Jaminan Sosial Kesehatan (BPJS Kesehatan). Salah satu program JKN adalah Program Rujuk Balik (PRB), yang diperuntukkan bagi pasien penyakit kronis dengan keadaan stabil yang masih memerlukan pengobatan jangka panjang. Semua peserta PRB berhak mendapatkan pengobatan untuk 30 hari penuh dari Apotek yang telah bekerjasama dengan BPJS Kesehatan, namun ternyata masih ada pasien yang tidak mendapatkan obat secara penuh. Penelitian ini bertujuan untuk melihat jumlah pemenuhan dan pola penggunaan obat PRB di Apotek wilayah Gedebage. Penelitian kuantitatif ini dilakukan di Wilayah Gedebage. Dua Apotek telah dipilih sebagai objek penelitian. Data berasal dari form resep obat bulan Oktober 2015, yaitu nama obat, indikasi (sesuai Formularium Nasional), jumlah obat, dan frekuensi penggunaan obat dari kedua Apotek. Lebih dari 95\% semua pelayanan obat PRB telah dilakukan oleh pihak Apotek yang bekerjasama dengan BPJS Kesehatan dengan pola penggunaan obat terbanyak yaitu untuk hipertensi sebanyak 84,09\%, disusul diabetes melitus $(37,52 \%)$ dan penyakit jantung $(12,72 \%)$. Secara umum, jumlah pemenuhan obat PRB untuk kebutuhan selama 30 hari dapat terpenuhi di kedua apotek dengan penggunaan obat terbanyak untuk penyakit hipertensi.
\end{abstract}

Kata Kunci: Apotek, BPJS Kesehatan, Obat PRB

\section{Fulfillment of Treatments and Drug Use Patterns in Referral Programs of Pharmacies in Gedebage Region, Bandung City}

\begin{abstract}
In early 2014, Indonesia's National Health Insurance or Jaminan Kesehatan Nasional (JKN) has implemented and it is organized by the Badan Penyelenggara Jaminan Sosial Kesehatan (BPJS Kesehatan). One of the programs in $J K N$ is the back-referral program or Program Rujuk Balik (PRB) that is reserved for stable patients with chronic disease who still needs long-term prescription. All PRB participants have a right to receive full treatment for 30 days from pharmacies that collaborate with BPJS Kesehatan, but there are still patients who do not obtain full treatment. This study is conducted to observe the number of filled prescription and the pattern of drug use by PRB pharmacies in the Gedebage region. his research was conducted in the Gedebage region using a quantitative method. Two pharmacies were chosen as research objects. The collected data was prescription form on October 2015 which consisted of the type of medicine, its indication (according to the National Formulary), the amount of medicine and the frequency of medicine prescription from both pharmacies. More than $95 \%$ from all PRB treatment services had been filled by pharmacies that collaborate with BPJS Kesehatan with the highest pattern of drug usage for hypertension (84.09\%), followed by diabetes mellitus (37.52\%) and heart disease (12.72\%). In general, the amount of PRB treatment for 30 days had been filled by pharmacies with the highest drug use for hypertension.
\end{abstract}

Keywords: BPJS Kesehatan, Pharmacy, PRB Treatment

\footnotetext{
Korespondensi:

Surya Dwi Sembada

Fakultas Kedokteran Universitas Padjadjaran

Jl. Prof. Dr. Eyckman No. 38 Bandung 40161

Mobile : 085351308968

Email : suryadjasmar@gmail.com
} 


\section{Pendahuluan}

Semua Warga Negara Indonesia berhak mendapatkan pelayanan kesehatan, hal ini tercantum pada Undang-Undang Dasar Negara Republik Indonesia tahun 1945 yang merupakan landasan konstitusional Sistem Kesehatan Nasional (SKN). ${ }^{1,2}$ SKN bertujuan untuk meningkatkan derajat kesehatan masyarakat yang setinggi-tingginya dengan menyelenggarakan pembangunan kesehatan secara sinergis, berhasil guna dan berdaya guna oleh semua potensi bangsa, baik pemerintah, dan/atau masyarakat termasuk badan hukum, badan usaha, maupun lembaga swasta. ${ }^{2}$ Sebagai upaya untuk mewujudkan tujuan SKN tersebut, dibentuklah pengelolaan kesehatan yang terbagi menjadi beberapa subsistem, salah satunya adalah subsistem sediaan farmasi, alat kesehatan, dan makanan. ${ }^{2}$

Mengacu pada Sistem Jaminan Sosial Nasional (SJSN) mengenai jaminan kesehatan, Indonesia memberlakukan Jaminan Kesehatan Nasional (JKN) yang dikelola oleh Badan Penyelenggara Jaminan Sosial Kesehatan (BPJS Kesehatan) pada awal tahun 2014 lalu, agar semua penduduk memperoleh pelayanan kesehatan yang layak. Salah satu pelayanan yang didapatkan peserta BPJS Kesehatan adalah pelayanan Program Rujuk Balik (PRB) yaitu pasien penyakit kronis dengan kondisi stabil berhak memperoleh pengobatan jangka panjang untuk kebutuhan maksimal 30 hari setiap kali peresepan. Terdapat 9 jenis penyakit yang termasuk dalam PRB, yaitu hipertensi, diabetes melitus, penyakit jantung, stroke, asma, penyakit paru obstruksi kronik, epilepsi, skizofren, dan lupus eritematosus sistemik. ${ }^{3-6}$ Berdasarkan peraturan BPJS Kesehatan, kebutuhan obat pada pelayanan PRB merupakan tanggung jawab BPJS Kesehatan dan apotek yang telah bekerjasama dengan BPJS Kesehatan yang mengacu pada Formularium Nasional. Namun menurut hasil rapat kerja kesehatan daerah Provinsi Jawa Tengah, dilaporkan bahwa ada permasalahan yang timbul dari PRB, yaitu pasien mendapatkan obat untuk kebutuhan kurang dari 30 hari, yang mengakibatkan pasien harus berulang kali ke fasilitas kesehatan dan apotek untuk mendapatkan obat secara penuh. ${ }^{5}$

Penelitian ini bertujuan untuk mengetahui jumlah pemenuhan dan pola penggunaan obat PRB di apotek Wilayah Gedebage, Kota Bandung. Penelitian ini dilakukan di Wilayah Gedebage Kota Bandung karena belum adanya data mengenai jumlah pemenuhan dan pola penggunaan obat PRB di Kota Bandung dan juga sebagai bahan evaluasi baik untuk BPJS Kesehatan maupun pihak apotek. Selain itu, Kota
Bandung adalah ibukota Provinsi Jawa Barat yang merupakan Provinsi percontohan pelaksanaan BPJS Kesehatan dan Wilayah Gedebage merupakan salah satu wilayah yang termasuk dalam penelitian besar bersama dengan Wilayah Cibeunying, Ujungberung, dan Bojonegara.

\section{Metode}

Penelitian ini menggunakan metode kuantitatif yang dilakukan di apotek yang telah bekerjasama dengan BPJS Kesehatan. Populasi pada penelitian ini adalah semua apotek di Wilayah Gedebage Kota Bandung yang telah bekerjasama dengan BPJS Kesehatan. Dengan menggunakan teknik total sampling, didapatkan 2 (dua) apotek yang menjadi objek pada penelitian ini yang kebetulan berasal dari manajemen yang sama.

Di kedua apotek ini, resep PRB disimpan terpisah dengan resep umum sehingga memudahkan pengambilan data. Data yang diambil dari form resep PRB yang masuk ke masing-masing apotek pada bulan Oktober 2015 terdiri dari nama obat, indikasi (sesuai dengan Formularium Nasional), jumlah obat, dan frekuensi penggunaan obat. Data yang diperoleh diseleksi berdasarkan kriteria inklusi, yaitu resep obat PRB pada bulan Oktober 2015 yang termasuk dalam Formularium Nasional (Fornas) dan kriteria eksklusi, yaitu jenis obat yang memiliki restriksi pemberian obat berdasarkan indikasi dan jumlah. Seperti obat klopidogrel dan simvastatin yang hanya dapat diberikan jika ada hasil laboratorium jantung dan kadar LDL. 7,8 Penelitian ini sudah disetujui oleh Komisi Etik Penelitian Kesehatan Fakultas Kedokteran Universitas Padjadjaran dan Informed consent telah dilakukan pada penanggung jawab Apotek sebelum pengambilan data dilakukan.

Analisis statistik pada penelitian ini menggunakan teknik statistik deskriptif dan disajikan dalam bentuk tabel, yaitu untuk melihat jumlah pemenuhan obat dari resep obat PRB dan distribusi frekuensi untuk melihat pola penggunaan obat PRB.

\section{Hasil}

Dalam pengambilan data yang dilakukan selama satu bulan, diperoleh 4319 resep dengan 1911 indikasi (sesuai Formularium Nasional) pada 2 apotek yang menjadi objek penelitian, dengan rincian 3691 resep dengan 1630 indikasi berasal dari Apotek A, dan 628 resep dengan 281 indikasi berasal dari Apotek B. Dari total 4319 resep, sebanyak 84 resep dari Apotek A dan 10 
resep dari Apotek B dieksklusi pada penelitian ini. Untuk mengetahui indikasi tiap obat yang tertera dalam resep, peneliti menyesuaikan dengan Fornas, selain itu juga melakukan konsultasi dengan apoteker. Selanjutnya, data yang masuk dalam kriteria inklusi diolah menggunakan analisis statistik deskriptif untuk mengetahui jumlah pemenuhan obat Program Rujuk Balik (PRB) dan tabel distribusi frekuensi untuk melihat penggunaan obat PRB. Kedua apotek yang menjadi objek pada penelitian ini merupakan apotek yang sama, dimana Apotek A sebagai apotek pusat dan Apotek B sebagai apotek jejaring. Sebagai apotek pusat, Apotek A berperan dalam mendistribusikan obat PRB ke apotek jejaring.

Bias informasi dapat terjadi pada penelitian ini, seperti resep yang tidak terbaca jelas atau keterangan pemberian obat tidak dicantumkan oleh apoteker. Untuk mengatasi hal tersebut, komunikasi antara peneliti dan apoteker yang bertugas sering dilakukan agar bias informasi ini dapat diminimalisir.

Berdasarkan tabel 1, jumlah pelayanan obat hipertensi sebesar $97,75 \%$, seharusnya mencapai $99,37 \%$. Sebanyak 843 obat antihipertensi tidak diberikan kepada pasien karena di Apotek hanya tersedia obat dengan dosis lebih besar daripada yang diresepkan, sehingga obat yang diberikan kepada pasien adalah setengah dari jumlah obat yang tercantum dalam resep. Begitu pun dengan obat untuk penyakit jantung dan asma, seharusnya mencapai 98,76\% dan 99,3\% secara berurutan, karena 1470 obat untuk penyakit jantung dan 30 obat untuk asma yang tercantum pada resep hanya diberikan setengahnya, namun dengan dosis yang lebih besar. Dosis yang lebih besar dan meminumnya hanya setengah dosis yang tersedia (sesuai kebutuhan yang diresepkan) tidak akan berpengaruh pada hasil terapi kecuali untuk obatobat yang memang tidak boleh dipotong atau digerus.

Tabel 1 Jumlah Pemenuhan Obat Program Rujuk Balik Apotek A

\begin{tabular}{llccc}
\hline No & \multicolumn{1}{c}{ Penyakit } & $\begin{array}{c}\text { Jumlah Tablet dalam } \\
\text { Resep }\end{array}$ & $\begin{array}{c}\text { Jumlah Tablet yang } \\
\text { Diberikan }\end{array}$ & Persentase \\
\hline 1 & Penyakit Jantung & 19130 & 18162 & $94,95 \%$ \\
2 & Stroke & 3250 & 3150 & $96,92 \%$ \\
3 & Hipertensi & 61715 & 60327 & $97,75 \%$ \\
4 & Lupus Eritematosus Sistemik & 5035 & 4930 & $97,91 \%$ \\
5 & Asma & 1513 & 1486 & $98,22 \%$ \\
6 & Diabetes Melitus & 51962 & 51710 & $99,52 \%$ \\
7 & Penyakit Paru Obstruksi Kronis & 60 & 60 & $100 \%$ \\
8 & Epilepsi & 0 & 0 & - \\
9 & Skizofren & 0 & 0 & - \\
\hline
\end{tabular}

Tabel 2 Jumlah Pemenuhan Obat Program Rujuk Balik Apotek B

\begin{tabular}{llccc}
\hline No & \multicolumn{1}{c}{ Penyakit } & $\begin{array}{c}\text { Jumlah Tablet dalam } \\
\text { Resep }\end{array}$ & $\begin{array}{c}\text { Jumlah Tablet yang } \\
\text { Diberikan }\end{array}$ & Persentase \\
\hline 1 & Hipertensi & 14645 & 14585 & $99,59 \%$ \\
2 & Diabetes melitus & 7598 & 7598 & $100 \%$ \\
3 & Penyakit Jantung & 1370 & 1310 & $100 \%$ \\
4 & Stroke & 90 & 90 & $100 \%$ \\
5 & Asma & 0 & 0 & - \\
6 & Penyakit Paru Obstruksi Kronis & 0 & 0 & - \\
7 & Epilepsi & 0 & 0 & - \\
8 & Skizofren & 0 & 0 & - \\
9 & Lupus Eritematosus Sistemik & 0 & 0 & - \\
\hline
\end{tabular}


Berdasarkan tabel 2, jumlah pelayanan untuk obat antihipertensi sebesar 99,59\%, seharusnya mencapai $100 \%$, hal ini dikarenakan 120 obat antihipertensi hanya diberikan setengahnya, namun dengan dosis yang lebih besar. Melihat hasil jumlah pemenuhan obat PRB di kedua apotek, jumlah pemenuhan obat PRB di Apotek B lebih baik daripada di Apotek A, padahal Apotek A merupakan apotek yang menjadi pusat distribusi obat PRB di beberapa apotek jejaring, termasuk Apotek B.

Pada tabel 3 dan 4 dicantumkan Pola Penggunaan Obat Program Rujuk Balik di apotek A dan $B$ yaitu penggunaan obat sesuai indikasi yang tercantum dalam fornas yang tertera pada resep obat.

\section{Pembahasan}

Pelayanan farmasi merupakan salah satu bagian yang berperan penting dalam keberhasilan Jaminan Kesehatan Nasional (JKN), terutama dalam keberhasilan Program Rujuk Balik (PRB). Pelayanan farmasi PRB untuk fasilitas kesehatan tingkat primer dapat dilakukan di Apotek atau ruang farmasi fasilitas kesehatan tingkat pertama yang bekerjasama dengan Badan Penyelenggara Jaminan Sosial Kesehatan (BPJS Kesehatan). Menurut Peraturan Menteri Kesehatan nomor 35 tahun 2014 tentang standar pelayanan kefarmasian di Apotek dan peraturan BPJS Kesehatan nomor 1 tahun 2014, pelayanan kefarmasian di Apotek meliputi kegiatan manajerial, salah satunya adalah pengelolaan sediaan farmasi dan BPJS Kesehatan memiliki kewajiban untuk menjamin kebutuhan obat yang diperlukan., ${ }^{4,9}$

Belum ada penelitian sebelumnya mengenai pelayanan obat di Apotek yang bekerjasama dengan BPJS Kesehatan. Menurut Ansharuddin dalam rapat konsultasi teknis direktorat bina pelayanan kefarmasian, terdapat beberapa komitmen kesediaan Apotek PRB. Pertama Apotek menjamin ketersediaan dan kecukupan obat PRB secara lengkap, kecuali ada pernyataan secara tertulis dari Distributor obat yang

Tabel 3 Pola Penggunaan Obat Program Rujuk Balik Apotek A

\begin{tabular}{llccc}
\hline No & \multicolumn{1}{c}{ Penyakit } & Jumlah Indikasi & Total Indikasi & Persentase \\
\hline 1 & Hipertensi & 1348 & 1630 & $82,7 \%$ \\
2 & Diabetes Melitus & 631 & 1630 & $38,71 \%$ \\
3 & Penyakit Jantung & 236 & 1630 & $14,48 \%$ \\
4 & Lupus Eritematosus Sistemik & 127 & 1630 & $7,79 \%$ \\
5 & Stroke & 111 & 1630 & $6,81 \%$ \\
6 & Asma & 42 & 1630 & $2,58 \%$ \\
7 & Penyakit Paru Obstruksi Kronis & 1 & 1630 & $0,06 \%$ \\
8 & Epilepsi & 0 & 1630 & $0 \%$ \\
9 & Skizofren & 0 & 1630 & $0 \%$ \\
\hline
\end{tabular}

Tabel 4 Pola Penggunaan Obat Program Rujuk Balik Apotek B

\begin{tabular}{llccc}
\hline No & \multicolumn{1}{c}{ Penyakit } & Jumlah Indikasi & Total Indikasi & Persentase \\
\hline 1 & Hipertensi & 259 & 281 & $92,17 \%$ \\
2 & Diabetes Melitus & 86 & 281 & $30,6 \%$ \\
3 & Penyakit Jantung & 7 & 281 & $2,49 \%$ \\
4 & Stroke & 3 & 281 & $1,07 \%$ \\
5 & Asma & 0 & 281 & $0 \%$ \\
6 & Penyakit Paru Obstruksi Kronis & 0 & 281 & $0 \%$ \\
7 & Epilepsi & 0 & 281 & $0 \%$ \\
8 & Skizofren & 0 & 281 & $0 \%$ \\
9 & Lupus Eritematosus Sistemik & 0 & 281 & $0 \%$ \\
\hline
\end{tabular}


bersangkutan jika obat dalam keadaan kosong. Kedua, Apotek memberikan obat-obatan kepada peserta berdasarkan resep obat yang diterima dengan tetap berpedoman kepada Formularium Nasional (Fornas). ${ }^{10}$

Jumlah pemenuhan obat PRB yang diberikan di Apotek yang bekerjasama dengan BPJS Kesehatan mencapai lebih dari $95 \%$ pada setiap penyakit PRB yang masuk ke Apotek yang menjadi objek penelitian ini. Meskipun tidak semua nama obat yang tercantum dalam resep tersedia di Apotek, pihak Apotek tetap dapat mencapai jumlah pemenuhan yang hampir $100 \%$. Strategi yang dilakukan oleh pihak Apotek adalah dengan memberikan obat lain yang kandungannya sama dengan nama obat yang tercantum pada resep obat. Dari sembilan penyakit yang terdapat dalam $\mathrm{PRB}$, ada 7 indikasi penyakit yang ditemukan pada resep obat PRB di kedua Apotek, yaitu hipertensi, diabetes melitus, penyakit jantung, stroke, asma, Penyakit Paru Obstruksi Kronis (PPOK), dan lupus eritematosus sistemik.

Hipertensi merupakan penyakit yang paling banyak ditemukan, dengan total di kedua Apotek sebesar 1607 resep atau 84,09\%, disusul oleh diabetes melitus $(37,52 \%)$, penyakit jantung $(12,72 \%)$, lupus eritematosus sistemik $(6,65 \%)$, stroke $(5,97 \%)$, asma $(2,2 \%)$, dan yang terakhir adalah PPOK sebesar $0,05 \%$. Dengan melihat pola penggunaan obat pada resep obat PRB yang masuk, secara tidak langsung dapat melihat prevalensi pada penyakit yang masuk kedalam PRB. Namun ternyata, urutan penyakit pada pola penggunaan obat PRB ini berbeda dengan prevalensi yang ada pada Riset Kesehatan Dasar (Riskesdas) pada tahun 2013 hal ini bisa diakibatkan karena metode yang dilakukan pada Riskesdas berbeda dengan metode pada penelitian ini. Pada Riskesdas dilihat berdasarkan wawancara terdiagnosis dokter atau gejala. Meskipun hasil Riskesdas merupakan prevalensi di provinsi Jawa Barat, bukan spesifik untuk Kota Bandung, namun diharapkan dapat mewakili prevalensi sebenarnya di Kota Bandung. Pada Riskesdas tahun 2013, dari 9 penyakit yang masuk dalam PRB, penyakit dengan prevalensi tertinggi adalah hipertensi $(29,4 \%)$, diabetes melitus berada diposisi kelima setelah stroke, asma, PPOK dengan prevalensi sebesar $2 \%{ }^{11}$

Keterbatasan pada penelitian ini yaitu diagnosis tidak dapat dipastikan secara pasti jika hanya dilihat dari jenis obat yang diresepkan, meskipun jenis-jenis obat yang tercantum merujuk pada suatu penyakit tertentu, karena satu obat yang diberikan kepada pasien tidak hanya untuk satu penyakit saja, obat tersebut mungkin diberikan untuk beberapa indikasi penyakit.
Berdasarkan hasil penelitian tentang jumlah pemenuhan dan pola penggunaan obat PRB di Apotek yang bekerjasama dengan BPJS Kesehatan di Wilayah Gedebage Kota Bandung, bahwa jumlah pemenuhan obat PRB sudah mencapai lebih dari 95\%, dan untuk beberapa penyakit sudah mencapai 100\%. Jumlah obat PRB untuk kebutuhan 30 hari sudah dapat dipenuhi oleh kedua apotek yang menjadi objek pada penelitian ini, namun masih ada beberapa obat yang tertera pada resep obat PRB yang belum dapat dipenuhi oleh Apotek A. Setelah hampir 2 tahun JKN yang diselenggarakan oleh BPJS Kesehatan berlangsung, diharapkan pelayanan obat PRB ini dapat lebih dioptimalkan. Sehingga jumlah pemenuhan semua obat PRB dapat mencapai $100 \%$ dan pasien mendapatkan jumlah obat yang sesuai dengan apa yang diresepkan oleh dokter, yang tentunya berdasarkan Fornas. Selain itu, diharapkan adanya sosialisasi dari pihak pemerintah, khususnya BPJS Kesehatan kepada dokter di fasilitas kesehatan yang bekerjasama dengan BPJS Kesehatan mengenai pedoman penerapan Fornas, karena masih ada beberapa dokter yang memberikan resep obat PRB yang merupakan restriksi penggunaan, baik itu restriksi berdasarkan jumlah maksimal pemberian atau pembatasan indikasi.

Merujuk pada hasil pola penggunaan obat PRB pada penelitian ini, diharapkan adanya koordinasi yang lebih baik antara BPJS Kesehatan dengan pihak Apotek mengenai distribusi dan ketersediaan obat PRB. Seperti mempersiapkan obat antihipertensi dan antidiabetes lebih banyak agar pemenuhan obat untuk pasien dapat dilakukan secara optimal.

\section{Daftar Pustaka}

1. Republik Indonesia. Undang-Undang Dasar Republik Indonesia 1945.

2. Presiden Republik Indonesia. Peraturan Presiden No 72 tentang Sistem Kesehatan Nasional. 2012.

3. Tim Penyusun. Buku Pegangan Sosialisasi Jaminan Kesehatan Nasional (JKN) dalam Sistem Jaminan Sosial Nasional. 2014.

4. Direktur Utama BPJS Kesehatan. Peraturan Badan Penyelenggara Jaminan Sosial Kesehatan No 1 tentang Penyelenggaraan Jaminan Kesehatan. Jakarta: BPJS Kesehatan. 2014.

5. Andayani Budi Lestari. Pelaksanaan JKN oleh BPJS Kesehatan Bulan Januari 2014. Semarang. 2014.

6. Direktur Utama BPJS Kesehatan. Program Rujuk Balik bagi Peserta JKN. Jakarta: BPJS 
Kesehatan. 2014.

7. Menteri Kesehatan Republik Indonesia. Formularium Nasional. Jakarta: Kementerian Kesehatan Republik Indonesia. 2013.

8. Direktur Jenderal Bina Kefarmasian Dan Alat Kesehatan. Pedoman Penerapan Formularium Nasional. Jakarta: Direktur Jenderal Bina Kefarmasian Dan Alat Kesehatan. 2014.

9. Menteri Kesehatan. Standar Pelayanan Kefarmasian di Apotek. Jakarta: Kementerian
Kesehatan RI. 2014.

10. Ansharuddin. Pola Kerjasama Apotek Jejaring dengan PPK Tingkat Pertama dan Apotek Dengan BPJS Kesehatan untuk Pelayanan Rujuk Balik. Semarang: 2014.

11. Kementerian Kesehatan Republik Indonesia. Riset kesehatan dasar 2013. Jakarta: Badan Penelitian dan Pengembangan Kesehatan, Kementerian Kesehatan Republik Indonesia. 2013. 